\title{
Features of the Introduction in Schools of Nonverbal Communication Development Programme for Children with Intellectual Disabilities
}

\author{
Oksana V. Zashchirinskaia* \\ Department of Pedagogics and Pedagogical Psychology, Saint Petersburg State University, Saint \\ Petersburg, Russian Federation
}

\begin{abstract}
Objective: The present study was conducted to identify the features of nonverbal communication in children.
Background: Nonverbal communication is a significant aspect of interpersonal communication. American scientists have found a strong correlation between low ability to recognise facial expressions, interpretation of postures, and gestures with communication difficulties. Experimental data indicate a positive relationship between the social status of an individual and the ability to interpret nonverbal signals. The general dynamics of the development of a child with disabilities are subject to the same laws as ordinary children. But the peculiarities of children associated with a disturbance of the intellectual sphere lead to the limitation of possibilities to obtain information from the outside world, a change in the methods of communication, difficulties of social adaptation, and impoverishment of social experience.
\end{abstract}

Method: Students of the first-grades of educational institutions of St. Petersburg were the survey sample. Several public and special schools were randomly selected in order to form the most detailed picture of the development of nonverbal behaviour in children, as well as to obtain the most representative sample for our study. A total of 128 children took part in the study - students of the first-grade (average age -7.4 years; 47 girls, 81 boys).

Results: A programme of psychological influence was developed to optimise the nonverbal communication of children with intellectual disabilities.

Conclusion: With psychological influence aimed at the development of nonverbal communication among primary schoolers with intellectual disabilities, more intact mental functions associated with the implementation of emotional and behavioural components were taken into account.

Keywords: Students with intellectual disabilities, inclusive education, nonverbal communication methods, children with special educational needs.

\section{INTRODUCTION}

For the period from 1991 to 2000 in Russia, the frequency of diagnoses of "developmental disability" in children has increased to 139.8 per 100 thousand populations. In this context, the authors are referring to primary school-aged children according to the age periodisation of A.A. Reana. At the same time, in $75 \%$ of cases, a slight degree of decrease in intelligence was noted. Among the indicated group of children, persistent underdevelopment of cognitive activity in 75$90 \%$ is determined by organic damage to the central nervous system. An epidemiological study of the mental state of children born between 1996 and 2013 published in 2017 indicates that mental retardation occurs in $1-1.5 \%$ of those born. According to the Ministry of Education and Science of the Russian Federation, over $60 \%$ are classified as at risk of somatic and psychophysical maladjustment among primary schoolers. In $35 \%$ of them, even in preschool age, disorders of the neuropsychic sphere are found.

*Address correspondence to this author at the Saint Petersburg State University, Saint Petersburg, Russian Federation; Tel: +7812 36366 33; E-mail: zashchirinskaia5112@ubogazici.in
The number of students who do not meet the general education programme requirements has increased 22.5 times over the past 20 years, reaching $20-40 \%$. The researchers emphasise that the deterioration in the health of students becomes one of the reasons for the difficulties in the development of their adaptive and communicative potentials. Children with intellectual disabilities show a decrease in the ability to use verbal and various nonverbal means of communication, which have a compensatory value for the child's successful socialisation. A sufficient number of works have been devoted to studying the causes of such violations [1-6].

As a result of numerous modern psychological and medical studies, it has been revealed that there are several contradictions between:

theory and practice of medical psychology. This contradiction is expressed in the fact that in the implementation of programmes of psychological influence, the emphasis is shifted to the development of social behaviour, but conceptual approaches to the study of the psyche as a poly structural and multifunctional phenomenon are not sufficiently taken into account; 
- the problem of nonverbal communication of children with intellectual disabilities and methods of psychological influence [7], which implies an emphasis on the development of specific communication skills without optimal use of the compensatory potential of nonspeech means of communication with others, aimed at the development of nonverbal communication of children with intellectual disabilities in the period of adaptation to school;

the significance of this problem and the insufficient number of methods, technologies of psychological influence to improve communication resources and socialisation potential when working with children with intellectual disabilities [8].

All of the above made it possible to formulate the research problem - identifying the features of nonverbal communication in children with intellectual disabilities and testing the programme of psychological influence to increase the effectiveness of psychological assistance to such children in the educative process.

The modern approach to the study of developmental disability is characterised by several features. First, intellectual disability is defined not as a disease, but as a state of mental underdevelopment, since it does not represent a decrease in mental functions due to a disease, but their initial underdevelopment is due to a pathological effect on an underdeveloped brain. Most researchers agree on this [9-12]. Secondly, intellectual disability is understood as a group of pathologies of various etiologies, i.e., the term itself has a collective meaning. For example, G.I. Kaplan and B.J. Sadok considered this phenomenon a "behavioural syndrome" that does not have a single aetiology, mechanism, dynamics, prognosis and reflects society's attitude towards this group. Intellectual disability is characterised by general clinical features, the main of which is the general underdevelopment of all complex forms of mental activity, and is expressed in the malformation of cognitive processes (sensing, percipience, memory, imagination, thinking, speech, attention) and the adaptive abilities of the child. The emotional-volitional sphere, motor skills, personality, in general, suffer, social behaviour changes significantly.

The intellectual defect in such children is manifested primarily by impaired thinking: stiffness, difficulty in perceiving the essential properties and signs of objects and phenomena, inability to be distracted. They are also characterised by a weak regulatory role of thinking: they begin to perform work without having listened to the task to the end, without understanding its purpose, without an internal plan of action, with weak self-control. The attention of such children is characterised by insufficient randomness and purposefulness, narrowing of the volume, difficulties in concentration, and switching. There are also noticeable memory impairments. They are usually caused by an inability to retain perceived images or connect with past experiences, as researchers point out [13, 14]. Often, with a good ability for mechanical memorisation, a weakness of semantic and especially associative memory is observed. Mentally disabled children do not know how to use previously acquired knowledge and skills in practice. Underdevelopment of motor skills is manifested mainly by a lack of precise movements, especially small ones. Underdevelopment of speech is characteristic of intellectual deficiency, and the degree of its underdevelopment corresponds to the severity of the intellectual defect. In moderately and severely mentally retarded children, speech appears with a delay; in some of them, it does not appear at all. Almost all children have a certain kind of speech defects. Children's vocabulary is poor; speech is agrammatical.

\section{MATERIALS AND METHODS}

For the present study, a survey and analysis of the level of development of nonverbal communication of children with intellectual disabilities were conducted. In clinical psychology, mental retardation is considered from the position of studying the dynamics of the course of cognitive, emotional, and behavioural processes in conditions of dysontogenesis. When describing this phenomenon, among other intellectual disturbances, pathological manifestations of certain areas of the psyche and the entire psyche as a whole are indicated.

In the context of the study of nonverbal communication of primary schoolers with intellectual disabilities, attention will be paid primarily to mild mental retardation in children. Based on the goals and objectives of the study, not only the features of communication against the background of mental underdevelopment will be considered, but also the adaptive capabilities of children will be studied, with the help of which it is possible to compensate for the limitations that arise in the presence of an intellectual disability. The formulation of tasks and hypotheses 
implies a careful choice of clinical-psychological and experimental-psychological methods that will assess the current level of development of cognitive, emotional, and behavioural components and study all the dynamic components of nonverbal communication of the surveyed first-graders.

Comparing the results obtained when studying the level of development of nonverbal communication of children in the process of direct experimental psychological work, comparison with expert assessments will provide a complete picture of the communicative sphere of the examined children. This version of the diagnostic procedure made it possible to assess the dynamics of the development of nonverbal communication in first-graders. Students of the firstgrades of schools in St. Petersburg were the survey sample. The authors randomly selected several schools, ordinary and special, in order to form the most detailed picture of the development of nonverbal abilities of children in the city, as well as to obtain the most representative sample for the study.

A total of 128 children took part in the study - firstgrade students (average age -7.4 years; 47 girls, 81 boys). Among them - 30 children diagnosed with mild mental retardation (average age -7.5 years; 11 girls, 19 boys), mixed specific developmental disorders - 53 children (average age -7.4 years; 12 girls, 41 boys). The control group included 45 mentally healthy children (average age -7 years; 24 girls, 21 boys). Part of the calculations was carried out for three groups separately, while part of the calculations combined a group of children with mixed specific developmental disorders and a group of children with mild mental retardation. As a result, the study sample consisted of first-grade students from schools of St. Petersburg.

\section{RESULTS}

In addition to comparing the obtained factors of three groups (i.e., primary school-aged children with mixed specific developmental disorders, with mild mental retardation and a normal level of development), the authors also compared normally developing children and the combined group children with intellectual disabilities, using Student's t-test for independent and dependent samples.

At the stage of comparing the experimental and control groups before psychological influence, the following statistically significant differences were found: in the analysis of gestures, the cognitive component of nonverbal communication, expressed in reaction time, emotionally personal, and behavioural components (higher scores also corresponded to lower results) were statistically significantly higher in children with intellectual disabilities $(p<0.05)$, in communication situations the factors of the emotional-personal component of nonverbal communication, the behavioural component, and understanding of spatial relationships turned out to be statistically significantly higher in the group of normally developing children ( $p$ $<0.05$ ), while the cognitive component corresponding to the reaction time was higher in the group of children with intellectual disabilities $(p<0.05)$.

Regarding the parents' assessments, statistically significant differences were observed only for the factor of intrafamily interaction. In children with a normal level of intellectual development, its level is statistically significantly higher $(p<0.05)$.

In relation to teachers' assessments, statistically, significant differences are found in the cognitive and emotional, and personal components $(p<0.05)$ - these indicators are statistically significantly higher in normally developing children than in children with intellectual disabilities.

After the psychological influence, the comparative analysis showed the following statistically reliable results. In the analysis of gestures, the cognitive component of nonverbal communication, expressed in reaction time, emotionally personal, and behavioural components (higher scores also corresponded to lower results) were statistically significantly higher in children with intellectual disabilities $(p<0.05)$, in communication situations factors of the emotional and personal component of nonverbal communication, the behavioural component, and understanding of spatial relationships turned out to be statistically significantly higher in the group of normally developing children ( $p$ $<0.05$ ), while the cognitive component corresponding to the reaction time was higher in the group of children with intellectual disabilities $(p<0.05)$.

According to the expert assessments of parents, statistically, significant differences were also observed only in terms of the intrafamily interaction factor. In normally developing children, its indicator is statistically significantly higher $(p<0.05)$.

According to expert assessments of teachers, in relation to egocentrism, a statistically significantly higher level after psychological influence was found in 
children with a normal level of intellectual development $(p<0.050)$, while no differences were found in other parameters, which indicates the similarity of assessments in children from different groups. The results obtained are presented in more detail in Tables 1 and 2.
Comparative analysis of factors before and after exposure revealed that, according to experimental data and teachers' assessments, improvements are observed in all parameters $(p<0.05)$, while the expert assessments of parents do not reveal such a difference. These results generally correspond to the

Table 1: The Result of a Comparative Analysis of Groups by Factors before the Psychological Influence

\begin{tabular}{|c|c|c|c|}
\hline Factor & Group & Average & Std. deviation \\
\hline \multirow{2}{*}{ Cognitive component of nonverbal communication* } & ND & 2.11 & 1.91 \\
\hline & ID & 11.41 & 16.01 \\
\hline \multirow{2}{*}{ Emotional and personal component of nonverbal communication* } & ND & 2.37 & 0.88 \\
\hline & ID & 3.40 & 0.57 \\
\hline \multirow{2}{*}{ Behavioural component of nonverbal communication* } & ND & 3.33 & 1.28 \\
\hline & ID & 3.88 & 1.41 \\
\hline \multirow{2}{*}{$\begin{array}{l}\text { Emotional and personal component of nonverbal communication in } \\
\qquad \text { situations }^{*}\end{array}$} & ND & 2.73 & 1.05 \\
\hline & ID & 1.05 & 0.81 \\
\hline \multirow{2}{*}{ Cognitive component of nonverbal communication in situations* } & ND & 3.21 & 5.76 \\
\hline & ID & 13.15 & 18.16 \\
\hline \multirow{2}{*}{ Understanding spatial relationships in situations ${ }^{*}$} & ND & 1.10 & 0.96 \\
\hline & ID & 0.33 & 0.63 \\
\hline \multirow{2}{*}{ Behavioural component of nonverbal communication in situations* } & ND & 1.70 & 1.20 \\
\hline & ID & 0.61 & 0.79 \\
\hline \multirow{2}{*}{ Communicative orientation (based on parental assessments) } & ND & 3.11 & 1.14 \\
\hline & ID & 3.03 & 0.96 \\
\hline \multirow{2}{*}{ Communication needs (based on parental assessments) } & ND & 3.56 & 1.26 \\
\hline & ID & 3.93 & 0.96 \\
\hline \multirow{2}{*}{ Directiveness of parents (based on parental assessments) } & ND & 2.80 & 0.88 \\
\hline & ID & 2.71 & 0.95 \\
\hline \multirow{2}{*}{ Intra-familial interaction* (based on parental assessments) } & ND & 2.96 & 1.56 \\
\hline & ID & 2.26 & 1.38 \\
\hline \multirow{2}{*}{$\begin{array}{l}\text { Cognitive component of nonverbal communication* (based on } \\
\text { teacher's assessments) }\end{array}$} & ND & 2.33 & 0.73 \\
\hline & ID & 1.63 & 0.79 \\
\hline \multirow{2}{*}{$\begin{array}{l}\text { Behavioural component of nonverbal communication (based on } \\
\text { teacher's assessments) }\end{array}$} & ND & 1.31 & 0.54 \\
\hline & ID & 1.44 & 0.64 \\
\hline \multirow{2}{*}{$\begin{array}{l}\text { Emotional and personal component of nonverbal communication* } \\
\text { (based on teacher's assessments) }\end{array}$} & ND & 1.97 & 0.54 \\
\hline & ID & 1.65 & 0.80 \\
\hline \multirow{2}{*}{$\begin{array}{l}\text { Cognitive component of nonverbal communication (based on } \\
\text { teacher's assessments) }\end{array}$} & ND & 2.59 & 0.49 \\
\hline & ID & 2.41 & 0.80 \\
\hline \multirow{2}{*}{$\begin{array}{l}\text { Emotional and personal component of nonverbal communication } \\
\text { (based on teacher's assessments) }\end{array}$} & ND & 2.87 & 0.60 \\
\hline & ID & 2.77 & 0.82 \\
\hline \multirow{2}{*}{ Teachers: egocentrism } & ND & 3.36 & 0.66 \\
\hline & ID & 3.44 & 0.87 \\
\hline
\end{tabular}

Note: ${ }^{*}-p<0,05$

Contracted notations: ND — children with normal intellectual development; ID — children with intellectual disabilities. 
Table 2: The Result of a Comparative Analysis of Groups by Factors after Psychological Influence

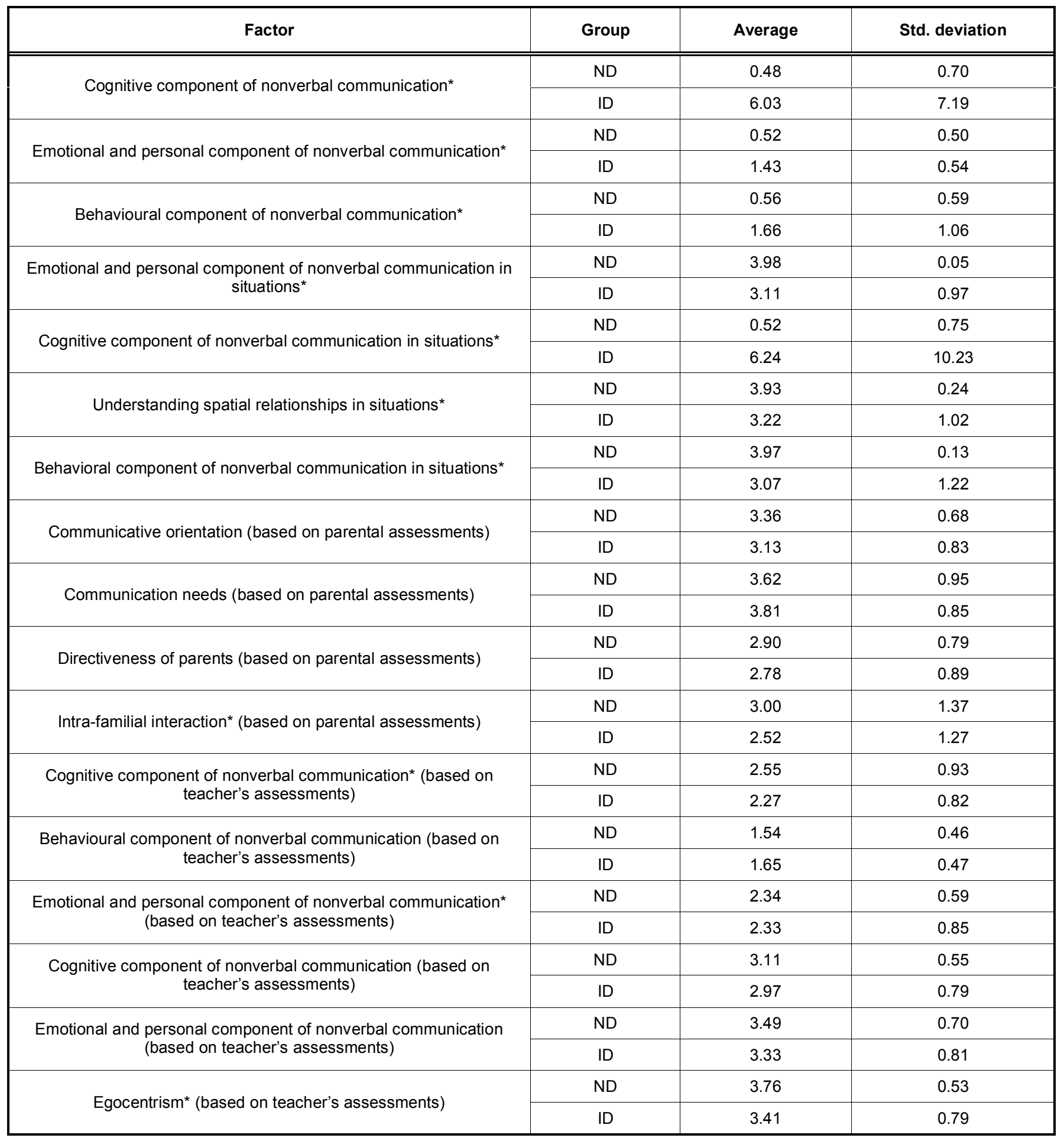

Note: * $-p<0,05$.

Contracted notations: ND — children with normal intellectual development; ID — children with intellectual disabilities

data obtained by comparing the three groups. It is also important to emphasise that the development of the emotional and personal component of communication in children with intellectual disabilities, according to the expert assessments of teachers, also confirms the effectiveness of the influence.
The experience of introducing a programme of psychological influence on the development of nonverbal communication in children with intellectual disabilities made it possible to formulate certain practical recommendations for specialists working in the field of medical psychology. 
1. Within the framework of psychological diagnostics of children with intellectual disabilities in order to assess the adaptive potential and individual opportunities for socialisation, it is important to study the developmental features of individual components of their nonverbal communication.

2. Psychological influence aimed at the development of nonverbal communication is planned not only taking into account the current level of the child's intelligence, but also its developmental dynamics in the process of targeted psychological influence.

3. Psychological assistance to children with disabilities is difficult and insufficient without the inclusion of technologies for the development of their communicative abilities, in particular, components of nonverbal communication.

4. The developed programme of psychological influence on the nonverbal communication of children with intellectual disabilities requires the development of their abilities in gestures recognition, designed to express their own emotional states and behavioural interaction, which increases the potential for adaptation to various social conditions and strengthens the formation of their vital interaction skills with people.

5. The empirical results obtained in the course of research suggest their application in the differential diagnosis of the communicative development of children with varying degrees of intellectual disability.

6. Developed and tested for effectiveness the programme of psychological influence to harmonise the development of nonverbal communication components is focused on the use in the work of clinical psychologists who provide assistance to children with intellectual disabilities. The programme tested in the framework of the study assumes an effective solution of tasks for the compensatory development of nonverbal communication in children with intellectual disabilities.

As part of the empirical study conducted, the authors managed to study the nonverbal communication of children with varying degrees of mental deficiency using a structural-dynamic approach, which made it possible to divide the sphere of nonverbal communication of a child into cognitive, emotional and personal and behavioural components.

\section{DISCUSSION}

The object of the study was to explore how family interactions can provide context for primary school children with intellectual and learning disabilities to develop social skills that can help them communicate with peers. As expected, children with disabilities found it more difficult to deal with family problems than their peers without disabilities. Children with intellectual disabilities tended to use fewer problem-solving skills and were less engaged in interactions [15]. However, regardless of disability status, the mothers' behaviour contributed to the development of the child's competent behaviour. Notably, mothers' positive problem solving, criticism, and active listening were associated with more active and engaged child problem solving, while mothers' directiveness was associated with worse problem solving and child involvement. Although fathers' behaviour was generally similar to that of mothers, only critical fathers' behaviour was associated with competent, proactive problem solving by children, and the effect was largely attributed to the families being compared [16].

These results are important for demonstrating the connection between family interactions and social adaptation of children outside the family during this period of development when peer interaction becomes more important and complex. The findings are also important for expanding family-peer bonds for children with intellectual and learning disabilities who are at high risk of peer difficulties. Specific, meaningful relationships between parental and child behaviour were broadly consistent with the familial processes assumed for children's learning and development of competent interpersonal skills. Notably, the association in which mothers who showed high levels of problemsolving behaviour had children who also showed high levels of problem-solving was consistent with a behavioural symmetry pattern where parents model competent behaviour that the children copy. There was also support for the learning process through additional forms of interaction. It is noteworthy that high rates of active listening by mothers in the form of seeking children's opinions and generalising their statements were associated with the more active participation of children in the discussion [17]. This pattern of complementary behaviour is consistent with the type of reciprocal parent-child discourse that has been 
identified in children with disabilities who have shown effective solutions to prosocial problems. Together, these symmetrical and complementary associations offer models of family interaction in which mothers model problem solving, ask for and confirm children's participation in the discussion, and children freely express their opinions and ideas about how to solve the problem. This type of parent-child exchange is consistent with the "horizontal" style of parent-child relationships that children can bring to their peer interactions.

PECS (Picture Exchange Communication System) is recognised as an effective tool for improving communication in children with autism. A peer study has shown that PECS training can significantly increase children's spontaneity. In this paper, we consider how exactly PECS training increased this communicative spontaneity. That is, the authors wanted first to investigate whether increased spontaneity is limited to communication using graphic symbols or whether PECS also affects the spontaneity of speech/vocalisation by children. Second, to find out if spontaneous communication enhancement was only used for instrumental purposes (such as snacking) or if children also spontaneously initiated communication for more social purposes as a result of PECS training. Third, to identify factors that could mitigate the effect of PECS learning and therefore predict which children might benefit most from learning. The Poisson regression analysis was used to examine the spontaneous communication of children using different communication modalities and different functions and to test the interaction between the intervention and the original variables. The naturalistic and relatively detailed measurement of the results indicated that it was possible to accurately analyse how PECS improved the spontaneity in children [18]. A small number of previous interventional studies have examined the communication patterns of children but have not focused solely on spontaneous, unhindered communication. The present analysis showed that while PECS training did result in children spontaneously communicating more with picture cards, it also resulted in increased spontaneity in children's speech use and a combination of picture card use and speech. The training appears to have increased spontaneous requests for items or help, but not spontaneous requests for social routines or comments. This programme cannot be complete without the development of methods for integrating nonverbal communication into a full-fledged educational process in mixed classes. For this, in the course of the study, the authors tried to develop all aspects of nonverbal communication for children with developmental disabilities.

\section{CONCLUSION}

Clinical psychologists can apply the main content of the programme of psychological influence on the development of nonverbal communication in children with intellectual disabilities in the process of adaptation to new learning conditions and communication as part of an integrated approach in interaction with other specialists working with children.

The results of the empirical study can be included in the content of student courses for the preparation of clinical psychologists who introduce the technology of non-medical psychotherapy into their practice. The empirical data obtained in the study will be useful in the following applied areas of specialists' activity:

- in teaching, in improving the professional competence of clinical psychologists when working with children with intellectual disabilities;

- $\quad$ for the practical work of clinical psychologists in the field of differential diagnosis and psychological influence aimed at developing the components of nonverbal communication in children with intellectual disabilities.

\section{ACKNOWLEDGEMENTS}

None.

\section{REFERENCES}

[1] Wieland N, Green S, Ellingsen R, Baker BL. Parent-child problem solving in families of children with or without intellectual disability. Journal of Intellectual Disability Research 2014; 58: 17-30. https://doi.org/10.1111/jir.12009

[2] van der Ende J, Verhulst FC, Tiemeier H. Agreement of informants on emotional and behavioral problems from childhood to adulthood. Psychological Assessment 2012; 24: 293-300. https://doi.org/10.1037/a0025500

[3] Koo TK, Li MY. A guideline of selecting and reporting intraclass correlation coefficients for reliability research. Journal of Chiropractic Medicine 2016; 15(2): 155-163. https://doi.org/10.1016/j.jcm.2016.02.012

[4] Zashchirinskaia OV. Nonverbal communication of persons with mental retardation: theoretical outline of the problem from the standpoint of the cognitive-behavioral approach. Nauka. Thought: electronic periodical journal 2016; 6 (2): 80 87.

[5] Maller AR. The problem of integrating children with severe developmental disorders. Special Education 2015; 1(11): 190-193. 
[6] Mulatova NA, Ryabenchenko NN. Inclusive education of children with intellectual disabilities. International Journal of Experimental Education 2016; 4: 259-261.

[7] Metsala JL, Galway TM, Ishaik G, Barton VE. Emotion knowledge, emotion regulation, and psychosocial adjustment in children with nonverbal learning disabilities. Child Neuropsychology 2017; 23: 609-629. https://doi.org/10.1080/09297049.2016.1205012

[8] Bunning K, Smith C, Kennedy P, Grennham C. Examination of the communication interface between students with severe to profound and multiple intellectual disability and educational staff during structured teaching sessions. Journal of Intellectual Disability Research 2013; 57(1): 39-52. https://doi.org/10.1111/j.1365-2788.2011.01513.x

[9] Shamma A. Non Verbal Communication Skills of Children with Autism Spectrum Disorder. Electronic Theses, Projects, and Dissertations 2018; 6: 24

[10] Robinson OC. Sampling in interview-based qualitative research: A theoretical and practical guide. Qualitative Research in Psychology 2014; 11(1): 25-41. https://doi.org/10.1080/14780887.2013.801543

[11] Vitaskova K, Rihova A. Analysis of impaired nonverbal communication in people with autism spectrum disorder. Social Welfare Interdisciplinary Approach 2013; 3(2): 87-97.

[12] Konst MJ, Matson JL, Goldin RL, Williams LW. Socialisation and nonverbal communication in atypically developing infants and toddlers. Research in Developmental Disabilities 2014; 35: 3416-3422.

https://doi.org/10.1016/j.ridd.2014.08.024
[13] Aderka IM, Appelbaum-Namdar E, Shafran N, GilboaSchechtman EA communication-based intervention for nonverbal children with autism: What changes? Who benefits? Journal of Consulting and Clinical Psychology 2011; 79(4): 447-457. https://doi.org/10.1037/a0024379

[14] Floyd FJ, Olsen DL. Family-peer linkages for children with intellectual disability and children with learning disabilities. Journal of Applied Developmental Psychology 2017; 52: 203211. https://doi.org/10.1016/j.appdev.2017.08.001

[15] Barton-Hulsey A, Sevcik RA, Romski M. Narrative language and reading comprehension in students with mild intellectual disabilities. American Journal on Intellectual and Developmental Disabilities 2017; 122(5): 392-408. https://doi.org/10.1352/1944-7558-122.5.392

[16] Shalev M, Hetzroni OE. Factors predicting school staff's responsivity toward students with intellectual and developmental disability and complex communication needs. Research in Developmental Disabilities. https://doi.org/10.1016/j.ridd.2020.103677

[17] Rodgers JD, Warhol A, Fox JD, McDonald CA, Thomeer ML, Lopata C, Sheffield T. Minimal risk of internalising problems in typically developing siblings of children with highfunctioning autism spectrum disorder. Journal of Child and Family Studies 2016; 25(8): 2554-2561. https://doi.org/10.1007/s10826-016-0407-8

[18] Derrick B, White P. Comparing two samples from an individual Likert question. International Journal of Mathematics and Statistics 2018; 18(3): 1-13.

\section{DOI: https://doi.org/10.6000/2292-2598.2020.08.04.6}

(c) 2020 Oksana V. Zashchirinskaia; Licensee Lifescience Global.

This is an open access article licensed under the terms of the Creative Commons Attribution Non-Commercial License (http://creativecommons.org/licenses/by-nc/3.0/) which permits unrestricted, non-commercial use, distribution and reproduction in any medium, provided the work is properly cited. 